\title{
The Impact of Influencers in Consumer Decision-Making: The Fashion Industry
}

\author{
Siti Nurfadila \\ Universitas Mercu Buana
}

\section{Setyo Riyanto}

Universitas Mercu Buana

\begin{abstract}
The internet and social media play a key role in helping consumers finding items of their interest. Fashion companies are keenly trying to establish a strong presence in social media platforms, often, through collaborations with fashion influencers. The increasing popularity of influencers - and their strong impact on consumer choices - has led to a transformation of digital marketing in the fashion industry. This research article explores influencer marketing strategies used by the fashion companies, as well as the impact that media influencers can have on patters of consumer decision-making.
\end{abstract}

Keywords: Social media, Fashion industry, Influencer marketing, consumer behavior, consumer decisionmaking

\section{INTRODUCTION}

As with other sectors, the fashion industry has to adapt to the shifting influencer landscape. There was a time when fashion and trends were largely dictated by industry experts. Something was in season, or it wasn't. These days things aren't so clear cut. Customers have taken to social media. They've started fashion blogs, and become famous for their fashion photography on Instagram. They create their own mix and match styles, sharing them with their social following. In doing so, some have managed to acquire thousands, or even millions, of followers. Traditional opinion setters aren't as influential as they once were.

Social media has become a part of our globally connected world in multiple ways, and most recently the fashion industry is seeing a major shift in its inspiration for designs and trends, all thanks to social media and blogging sites like Facebook, Twitter, Instagram and Tumblr. ${ }^{1}$ In the fashion industry, social media platforms can be used to interact with the consumer, as a means of networking with others in the industry, and as a way of building an online presence. But social media can also influence designers in unique ways that are changing the way many designers create their fashions. It's not just the inspiration and influences on major fashion designers that social media is evolving; it's also the way we view fashion and the industry as a whole. For decades, a few big names dominated the fashion industry in a very top-down fashion but now the average fashion blogger can influence major designers via social media outlets.

1 Delaney, J., Salminen, N., \& Lee, E. (2012). Infographic: The Growing Impact of Social Media. 


\section{LITERATURE REVIEW}

\section{A. Digital marketing}

it is an component of marketing that utilizes internet and online based digital technologies such as desktop computers, mobile phones and other digital media and platforms to promote products and services. Its development during the 1990s and 2000s, changed the way brands and businesses use technology for marketing. As digital platforms became increasingly incorporated into marketing plans and everyday life, and as people increasingly use digital devices instead of visiting physical shops, digital marketing campaigns have become prevalent, employing combinations of search engine optimization, search engine marketing, content marketing, influencer marketing, content automation, campaign marketing, data-driven marketing, e-commerce marketing, social media marketing, social media optimization, e-mail direct marketing, display advertising, ebooks, and optical disks and games have become commonplace. Digital marketing extends to nonInternet channels that provide digital media, such as television, mobile phones, callback, and onhold mobile ring tones. The extension to non-Internet channels differentiates digital marketing from online marketing. ${ }^{2}$

In today's digital era, marketing a product involves competing against other companies in influencing the purchasing behavior of online consumers. A competency is a particular skill, knowledge, or characteristic necessary to perform a role effectively and to help a business meet its strategic objectives. Competence models are used to build leadership qualifications and improve effectiveness in relation to future business challenges. The main categories of competence include leadership, analytical thinking, communication, decision-making, relationship building, strategic planning or emotional intelligence. ${ }^{3}$

Social media platforms are a powerful tool in digital marketing campaigns as they allow companies to engage with followers and to advertise their products towards a tailored audience. In recent years, the fashion industry has gained exponential visibility in social media which in turn has resulted in many social media users developing an interest in fashion trends and events. The availability of different fashion outlets in digital platforms exposes users to a wide variety of domestic and international brands and trends, as well as influences users' purchasing behavior. The fashion industry is, thus, putting its focus on developing efficient digital marketing tools. This involves the innovative use of media and technology alongside with the most recent and popular fashion trends.

\section{B. Influencer Marketing}

Influencer marketing (a.k.a. influence marketing) is a form of social media marketing involving endorsements and product placement from influencers, people and organizations who have a purported expert level of knowledge or social influence in their field. Influencer content may be framed as testimonial advertising; influencers play the role of a potential buyer, or may be involved

\footnotetext{
Mohammed, R. (2001). Internet marketing. Mc Graw Hill, New York, Vol. 4.

Riyanto, S. \& Panggabean, M. (2019). The Impact of Leadership, Organizational Culture and Organizational Climate on Employee Job Satisfaction. Advances in Economics, Business and Management Research, 120.
} 
as third parties. These third parties can be seen in the supply chain (such as retailers or manufacturers) or as value-added influencers, such as journalists, academics, industry analysts, and professional advisers. ${ }^{4}$

Influencer marketing can be defined as a process of identifying and activating individuals who have an influence over a specific target audience or medium, in order to be part of a brand's campaign towards increased reach, sales, or engagement. Influencer marketing is an extension to the original concept of word-of-mouth marketing, focusing on a social context and performed in a more professional way. It is a form of relationship building which may be very helpful for brands that seek to expand their audience and turn them into loyal customers through trust and authenticity.

Influencer marketing tends to be broken into two sub practices: The first one is earned influencer marketing. It stems from unpaid or pre-existing relationships with influencers or third party content that is promoted by the influencer to further their own personal social growth. And the second one is paid influencer marketing: the Paid influencer marketing campaigns can take the form of sponsorship, pre-roll advertising or testimonial messaging and can appear at any point in the content. Budgets vary widely and are usually based on audience reach. Influence can come from a wide range of places. Any person, group, brand, or place could potentially be an influencer. Influencer marketing has many applications. Some marketers use influencer marketing to establish credibility in the market, others to create social conversations around their brand, others yet to drive online or in-store sales of their products. Therefore, the value that influencer marketing creates can be measured in multiple ways.

Some marketers use influencer marketing to establish credibility in a market; others use it to create social conversations about their brand, and still others focus on driving online or in-store sales. Marketers leverage credibility gained over time to promote a variety of products or services. They measure their success in several ways, including earned media value, impressions, and cost per action. ${ }^{5}$

As social learning theory suggests, influencers serve as informed consumers. When credible influencers match up with the product, consumers will consider their recommendations.

Consumers see influencers as a neutral authority assessing a product. Especially when compared to brand's ambassadors, influencers are exponentially perceived as more approachable and trustworthy. Because the majority of millennials and baby boomers prefer word of mouth over corporate advertisement, research shows that influencer marketing is more effective on younger demographics. With the rise of social media influencers, influencer marketing could become a trend on marketing strategies. ${ }^{6}$

4 Mowen, J.C. \& Minor, M. (2000). Consumer Behavior. 5th Edition, New York: Prentice Hall,.

5 Karimi, S. (2013)- A purchase decision-making process model of online consumers and its influential factor a cross sector analysis.

6 Google. (2012). The Customer Journey to Online Purchase. 


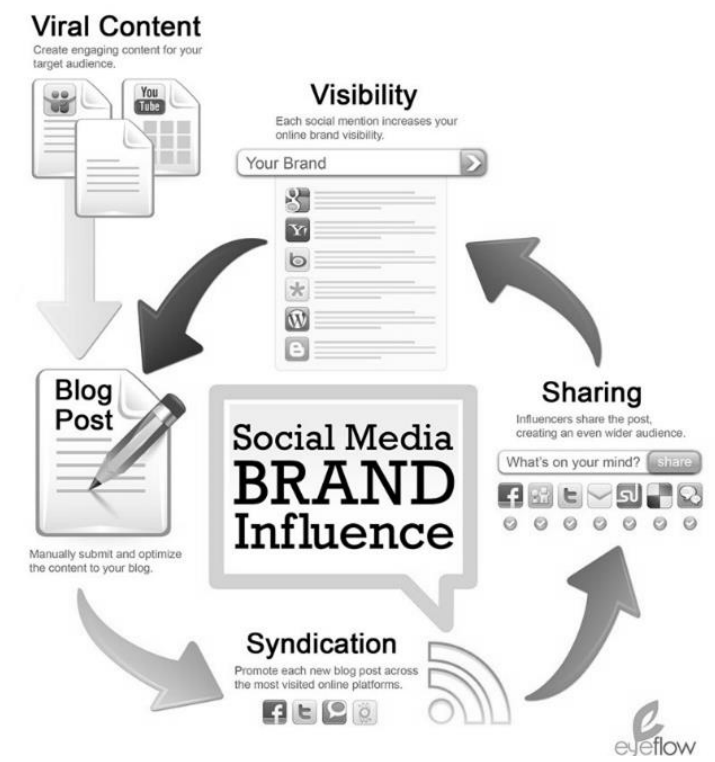

Source: www.clickz.com/wp-content/influence-posting

C. Platforms for influencers

The most pertinent platforms for influencers marketing are:

1. Instagram

Using Instagram influencers as a marketing channel can be a very effective and affordable way of marketing your product or business. People instinctively desire social proof. This makes consumers far more likely to purchase a product or service when it is recommended by an influencer they trust

2. YouTube videos

YouTubers upload numerous videos about fashion and beauty tips that are shared with people all over the world. These videos inspire viewers to try on these tips and techniques as they can simultaneously watch and do their own make-up.

3. Facebook

The idea behind influencer marketing on Facebook is, fundamentally, the same as influencer marketing on any other online platform. It starts with a brand identifying a Facebook user with a medium-to-large (and highly-engaged) follower base that overlaps with the brand's target audience. The brand then reaches out to the influential Facebook user to see if they're interested in posting about the brand's products.

4. Blogs

Fashion Blogs are usually maintained by an individual or business with regular entries of commentary, description of events, or other material such as graphics or video. 'Blog' can also be used as a verb, meaning to maintain or add content to a blog". Fashion blogging has become popular since 201l, blogs often cover the industry as a whole, personal style, reviews of clothing items and collections. Fashion bloggers have a very high status of legitimacy and those with large followings have power in the fashion world. 
5. Twitter, Linkedln, Pintrest, and many other apps are highly used today to sway how one understands and captures fashion. The photo apps are geared toward the younger generation. The reason for their success relies on their ease and their instantaneous qualities. For a generation that lives in a fast paced world, convenience and quickness is the key to success.

\section{The Consumers and Decision-Making in Fashion}

Consumers are actors on the market place stage. Consumers, in general, can be referred as individuals who purchase or consume products and services; however, in terms of buyer and consumer, there is a slight difference. Buyers are the people who are acting either as ultimate, industrial, or institutional purchasers. Consumer exhibits various behavior patterns during purchase process and disposing of goods, services, ideas or experiences. They are eagerly observing the cues of the fashion industries with which they can set perceptions for fulfilling their needs. Inevitably, businesses encounter bottlenecks where the message is not reaching their consumers and prospects, with the fact that, at times, consumers and prospects are facing significant blocks in their decision process. If not, each of them should be fully committed, loyal, enthusiastic, repeated consumers; however, this is not the case. Today the accessibility and transparency of information has profoundly influenced the decision making process; therefore, it is important to examine what are the hurdles and fiction points that hold prospects becoming consumers, or keeps consumers hesitating from repurchasing ${ }^{7}$. Fashion is of great importance to many consumers, it is defined as "the process of social diffusion by which a new style is adopted by some group of consumers." ${ }^{8}$ Fashion influences many aspects of our lives, it has both economic and social value and provides individuals with a tool to express themselves and create an identity. It is therefore important to understand the process of decision making within the fashion industry.

\section{E. Influencers and Decision Making}

Consumer's decision making within fashion is influenced by the information available in the society from many different sources like advertising, magazines, celebrities, online, friends, family and bloggers. Further, a fashion purchase is a devoted task that requires more detailed involvement from consumers. In today's society social influencers, like journalists, celebrities, bloggers, magazines and brand advocates, are regarded as "the most powerful force in the fashion marketplace." They impact customers purchasing decisions based on their personal opinion, ability and position and are often considered experts in their field by consumers. Social influencers therefore have a great deal of influence on consumers purchasing decisions and can influence what becomes a trend and a "must have" fashion as consumers tend to copy their style and believe that they are the experts within the product category. Consumers in today's society are therefore influenced by social influencers to a greater extent than before.

7 Stelzner, M.A. (2012). Social Media Marketing Industry Report: How Marketers Are Using Social Media to Grow Their Businesses. 


\section{HOW EFFECTIVE IS INFLUENCER MARKETING?}

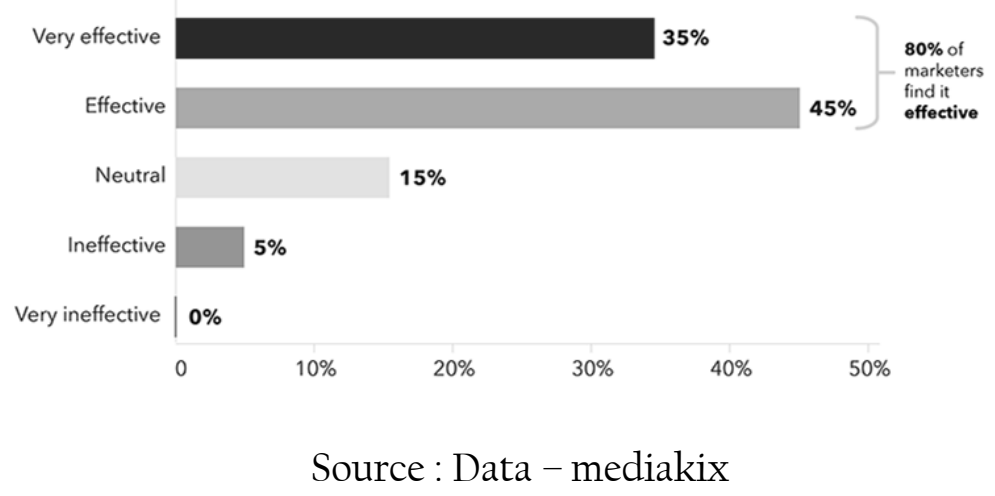

\section{THEORETICAL FRAMEWORK}

Digital marketing is an umbrella term for all online marketing efforts. Businesses leverage digital channels such as Google search, social media, email, and their websites to connect with their current and prospective customers. Digital marketing can work for any business in any industry. Regardless of the company sells, digital marketing still involves building out buyer personas to identify your audience's needs, and creating valuable online content. Today, monotonous advertising and marketing techniques have given way to digital Marketing. In addition, it is so powerful that it can help revive the economy and can create tremendous opportunities for governments to function in a more efficient manner.

Digital marketing is the use of technologies to help marketing activities in order to improve customer knowledge by matching their needs. Consumer behavior is defined as the study of the processes involved when individuals or groups select, purchase, use or dispose of products, services, ideas or experiences to satisfy needs and desire.

A person who has indicated his/ her willingness to obtain goods or services from a supplier with the intention of paying for them is called a Consumer (Solomon M. et al (2006). ${ }^{9}$ Schiffman and Kanuk $(2010)^{10}$ mentioned that the consumer made the purchase decision is influenced by several measurements, namely (1) the measurement of culture, which has the most influence and the most extensive in the behavior of consumers so that marketers need to understand the influence of culture, sub-culture, and social class of consumers; (2) social measurement, which need to be considered when designing a marketing strategy because these factors can affect consumer responses; (3) personal measurements, which consist of the age and stage of life cycle, occupation, economic situation, lifestyle, personality, and self-concept affects the consumer on

9 Delaney, J., Salminen, N., \& Lee, E. (2012). Infographic: The Growing Impact of Social Media.

10 Schiffman G. L. \& Kanuk L. L. (2009). Consumer Behavior. llth Edition, New Delhi: PrenticeHall of India, Pvt., Ltd. 
what is purchased; and (4) psychological measurement, include motivation, perception, learning and beliefs and attitudes also influence the selection of consumer purchases. ${ }^{11}$

Marketers now must understand how to "position themselves to benefit from fundamental changes that are occurring in the ways people decide on which products and services to consume, and how they actually consume them." It was stated that Fashion blogs dominate this communication in the fashion industry, enjoying the attention of users due to the platform's personal and interactive approach versus the standardized treatment through mainstream media. $^{12}$

A celebrity endorser is an individual who enjoys public recognition and who uses this recognition on behalf of a consumer good by appearing with it in an advertisement. ${ }^{13}$ Celebrity endorsement influences the feelings of the consumers and can also influence the attitude consumers have towards the advertisement and attitude towards the brands, which can increase the purchase intentions and, consequently, increase sales. Consumers trust the celebrity endorser to be credible, when a celebrity endorses one or two products it is significantly more trustworthy than a celebrity who endorses even more products. ${ }^{14}$ Hence he states that there is always the possibility of negative effect due to multiple endorsement programs by a single celebrity. superstar is considered like memorial, entertainer or representative of the business organization. Investigation has established that spokesperson endorsement influence consumers' mind-set in common and it may change the feelings of customers towards the commercial and products as well. This may perhaps effect in improvement of acquisition plan and as an outcome in increase of trade.

The trends in fashion change very often. Digital media, nowadays, is given such an importance that it redefines the fashion industry tremendously. A fashion world makes use of social media in a way that it invites bloggers to several fashion shows. Moreover, models contribute in generating a social media following, and the designers, on the other hand, make use of Instagram to inspire the people who look forward to a fashion in trend. Furthermore, the increasing numbers of influencers are being followed by a number of like-minded followers who tend to follow the fashion in a number of ways.

According to Sedeke, (2013) ${ }^{15}$ Fashion is a consistently changing industry with new products and trends being created and new designers itching to be publicized around the world at any given moment, making identification with loyal consumers and their preferences vital to any amount of success. As a low-cost form of distributing online media, specifically important to new designers whose budgets remain at lower capabilities, bloggers spend their time searching

11 Jacobs, D.L. (2013). Social Media Marketing: How to turn Satisfied Customers into 'Brand Advocates.

12 Sproles, G. B. \& Kendall, E. L. (1986). A methodology for profiling consumers decision making styles. Journal of Consumer Affairs, 20(2), 267-279.

13 Treme, J. (2010). Effects of Celebrity Media Exposure on Box-Office Performance, Journal of Media Economics, 23(1), 5-16

14 Ibid.

15 Mckinsey. (2009). The consumer Decision Journey. Mckinsey and Company. 
for high-quality information, including products and trends, to supplement a blog post to attract the largest audience possible.

\section{METHODOLOGY}

A comprehensive review of most pertinent past research papers about fashion industry and influencers on consumer behavior has been carried out and researchers understand that there are not many researches were conducted on the impact of influencers in fashion industry. Thus keeping in view the gap identified through review we set the following objectives: I) To identify how the fashion industry is currently using influencer marketing, ii) To study the impact of influencers on the consumers buying decision process in fashion industry, and iii) To find out the influencer marketing techniques used by fashion industries.

\section{A. Hypotheses}

The following research hypotheses are formulated to test the aforementioned objectives:

$\mathrm{Hl}$ : There is a significant difference between the use of various types of social media platforms in influencer marketing

H2: There are significant differences between marketing through influencers or through other marketing sources

H3: There is a significant use of social media in marketing by influencers

\section{B. Research Methodology}

The research was conducted on exploratory mode as there is no pre-defined problem but can provide significant insight into a given situation. A structured questionnaire is given to 200 women across all demographic areas based on judgmental and snow bowling technique. The research is not intended to provide conclusive evidence, but helps researchers to have a better understanding of the problem. The focus is on gaining insights and familiarity for later investigation.

\section{Data Collection Techniques}

Data collection is done using secondary data collected from the website and previous studies.

\section{OUTCOME}

In today's society even the apparel customers like fashion trend seekers are influenced by journalists, celebrities, bloggers, magazines and brand advocates and they are regarded as "the most powerful force in the fashion marketplace." They impact customers purchasing decisions based on their personal opinion, ability and position and are often considered experts in their field by consumers. 


\section{THE QUALITY OF CUSTOMERS / TRAFFIC FROM \\ INFLUENCER MARKETING IS BETTER THAN \\ OTHER MARKETING SOURCES:}

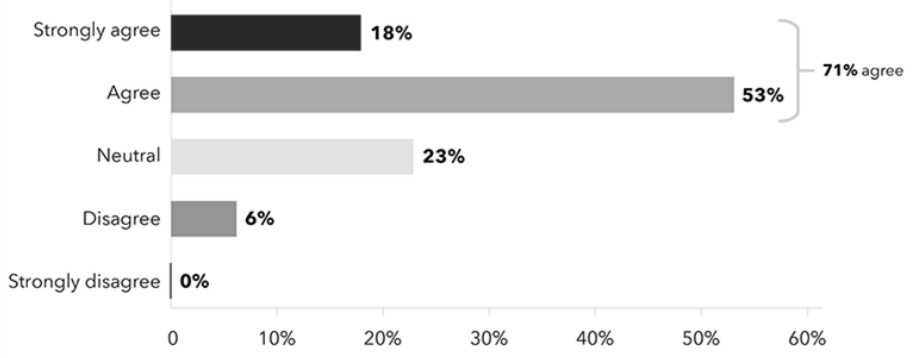

Source : Data-Mediakix

71\% Of Marketers Say The Quality Of Customers \& Traffic From Influencer Marketing Is Better Than Other Sources, Most marketers agree that the quality of visitors and customers from influencer marketing is better than other channels, and 18\% of marketers strongly agree with this sentiment-only 5\% disagree.

\section{COMPARED TO OTHER CHANNELS, ROI FROM INFLUENCER MARKETING IS...}

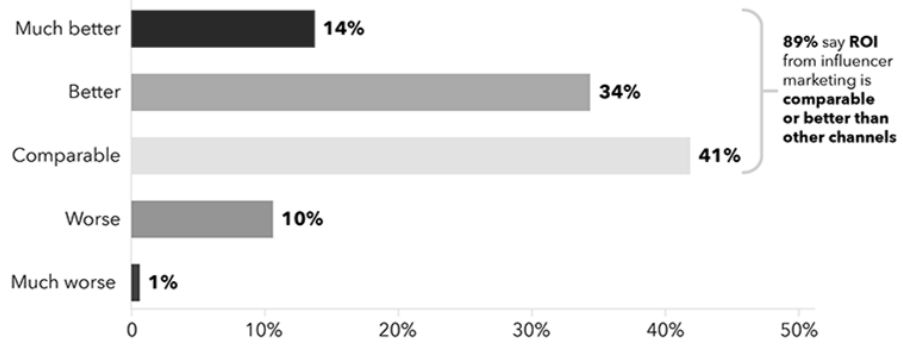

Source : data - mediakix

89\% Say ROI From Influencer Marketing Is Comparable To Or Better Than Other Marketing Channels, Nearly half (48\%) of marketers say that ROI from influencer marketing is better than other marketing channels, and $41 \%$ say returns are equal to other sources. As more marketers improve their measurement and optimize their tactics, we expect more marketers to improve their returns in 2019. 


\section{IN 2019, SPENDING ON INFLUENCER MARKETING WILL...}
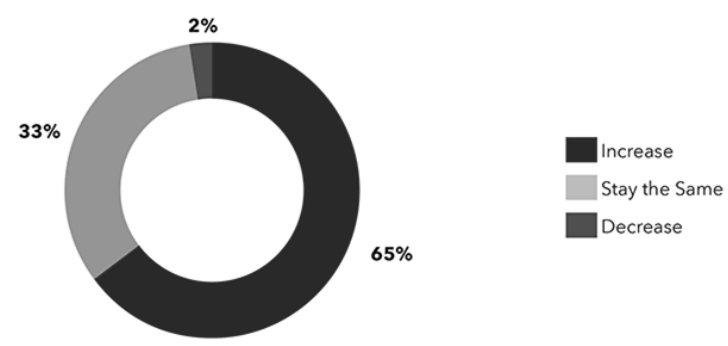

Source: Data - mediakix

65\% Of Influencer Marketing Budgets Will Increase In 2019

Last year, 39\% of marketers planned to increase their influencer marketing budgets for 2018. This year, confidence in influencer marketing appears to be notably stronger, as 65\% of marketers plan to increase their budgets for 2019-while only $2 \%$ will decrease.

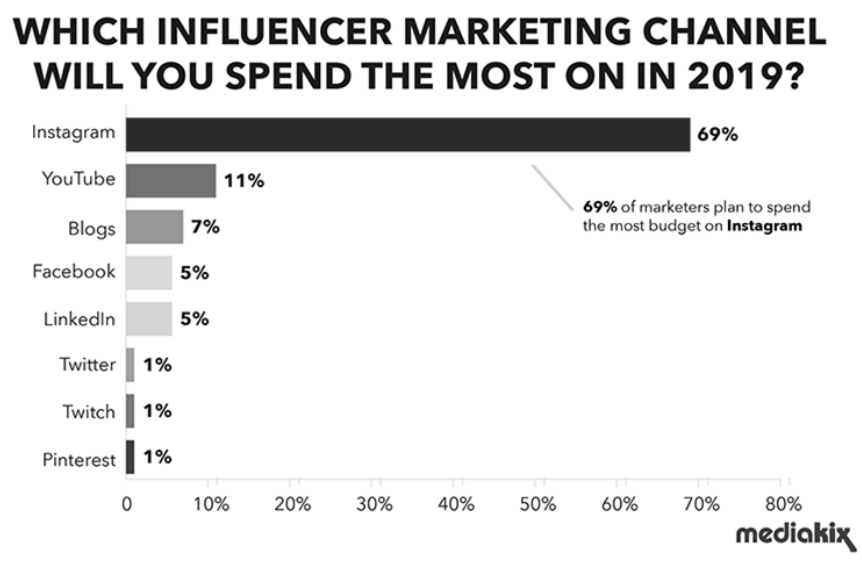

Source: Data - Mediakix

Over $2 / 3$ Of Marketers Will Spend The Most On Instagram In 2019

$69 \%$ of marketers plan to spend the most on Instagram in 2019-that's over 6X as much as YouTube $(11 \%)$, the second most-selected influencer marketing channel. This suggests that Instagram is not only strategically important to marketers, but will also be attracting the vast majority of influencer marketing ad spend in 2019. 


\section{DO YOU THINK INFLUENCER MARKETING \\ CAN BE AUTOMATED?}

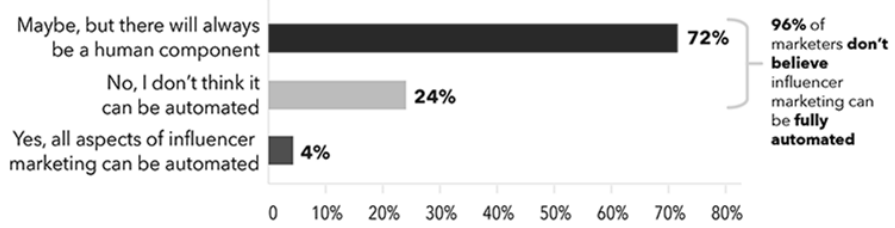

Source: Data - Mediakix

A. Looking Ahead

96\% Of Marketers Don’t Believe Influencer Marketing Can Be Fully Automated

The industry remains divided over whether such a deeply human channel can be fully automated in the future, but it appears that marketers are fairly certain that it can't. Only 4\% of marketers believe that all aspects of influencer marketing can be automated. The vast majority (72\%) believe that there will always be a human component, and 24\% don't believe it can be automated at all.

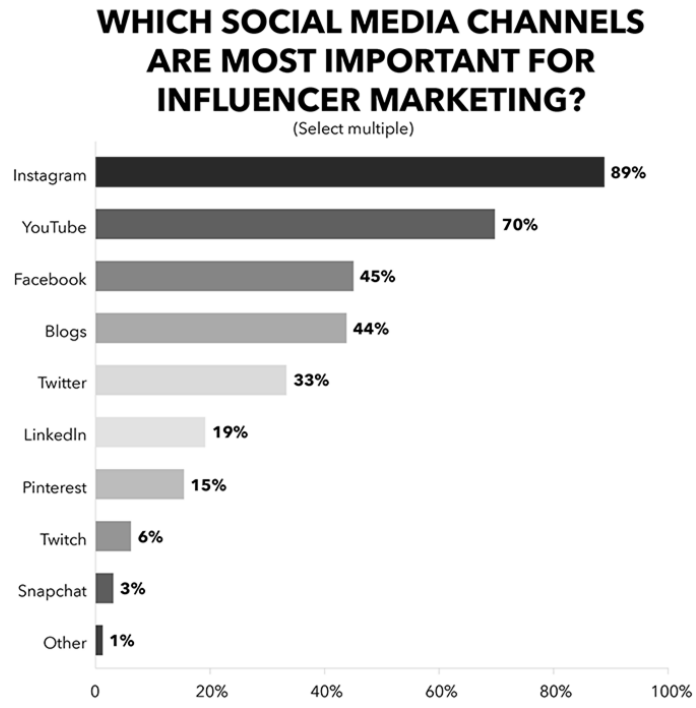

Source: Data - Mediakix

With The Success Of Stories, Instagram Solidifies Its Position As Most Popular Influencer Marketing Channel

Instagram Ranked The Most Important Influencer Marketing Channel In 2019. Since hitting 1 billion users in June of 2018, Instagram has only continued to innovate and grow. The launch of IGTV represented a concerted push into video, and several shopping features rolled out in September 2018 poised Instagram as a powerful revenue generator for e-commerce brands. The 
Instagram Stories feature in particular soared in 2018, with over double the number of active users compared to Snapchat.

Top five most strategically important social media channels:

Instagram: 89\%

YouTube: $70 \%$

Facebook: $45 \%$
Blogs: $44 \%$

Twitter: $33 \%$

\section{RECOMENDATION}

The present paper analyzes the impact of influencers in various stages of consumer decision process in fashion industry. In the beginning stages of the buying process, consumers tend to realize the need for the product by following celebrities in Facebook, Instagram, twitter etc. The consumers have used blogs as a way to find out information about the product they were considering buying. The blogs also increase the amount of communication consumer's conduct that occurs before the actual purchasing situation. With the use of blogs the phenomena of passing on the message is highlighted in its efficiency. Research responses also suggest that readers use blogs as a way of validating their purchasing decisions. They go online to find reviews posted by bloggers about the product they might be interested in buying and by using the communication tools of the blogs, they ask opinions from the blogger and other readers, hoping to get help to their decision making.

The results of the research indicate that social media can have a significant impact on how young women behave after reading a positive comment on a purchase, as they enjoy not only having are liable source telling them their opinions on the products and having a source of information, but also that they enjoy reading texts by someone they relate to. The style of the blogger is what draws the reader to a specific blog, it is the pictures that attract readers coming back and trusting their reviews. Bloggers often provide direct links to the specific items they are talking about and provide the consumers with tips on good and safe places to shop from.

This can be seen both as a negative and a positive shift in terms of the company. If the consumer is satisfied with the product, blogs can be a tool the customer uses to pass on a message about the good experience to unlimited amount people. Without blogs, consumers might talk about the product, but mainly only with their friends, limiting the number of potential customers to a very small number. Therefore by writing about the experiences on blogs, companies can get an idea of what they have done right and what they need to improve on, getting the customer point of view. It is important to note that several companies operating in the fashion industry have come to value and recognize the influence that bloggers can have in terms of reaching their target customers, and have found an efficient way of marketing their products. With these recommendations of investing into relationship building with a blogger and indirectly engaging 
the company's target customer base, company trust and customer loyalty can be built, resulting in higher sales and profitable long-term customer relationships.

\section{REFERENCES}

Delaney, J., Salminen, N., \& Lee, E. (2012). Infographic: The Growing Impact of Social Media.

Dugan., L. (2012). How Do Consumers Use Social Media to Shop?

Google. (2012). The Customer Journey to Online Purchase.

Jacobs, D.L. (2013). Social Media Marketing: How to turn Satisfied Customers into 'Brand Advocates.

Mohammed, R. (2001). Internet marketing. Mc Graw Hill, New York, Vol. 4.

Mowen, J.C. \& Minor, M. (2000). Consumer Behavior. 5th Edition, New York: Prentice Hall,.

Mckinsey. (2009). The consumer Decision Journey. Mckinsey and Company.

Roberto, M. A. \& Lynne C. L. (2005). Art of making change initiative sticks. Sloan Management Review, 46(4), 53-60

Karimi, S. (2013)- A purchase decision-making process model of online consumers and its influential factor a cross sector analysis.

Schiffman G. L. \& Kanuk L. L. (2009). Consumer Behavior. 1lth Edition, New Delhi: PrenticeHall of India, Pvt., Ltd.

Riyanto, S. \& Panggabean, M. (2019). The Impact of Leadership, Organizational Culture and

Organizational Climate on Employee Job Satisfaction. Advances in Economics, Business and Management Research, 120.

Sproles, G. B. \& Kendall, E. L. (1986). A methodology for profiling consumers decision making styles. Journal of Consumer Affairs, 20(2), 267-279.

Stelzner, M.A. (2012). Social Media Marketing Industry Report: How Marketers Are Using Social Media to Grow Their Businesses.

Treme, J. (2010). Effects of Celebrity Media Exposure on Box-Office Performance, Journal of Media Economics, 23(1), 5-16 